IRSH 49 (2004), pp. I22-I3I DOI: I0.1017/S002085900300I4IX

(C) 2004 Internationaal Instituut voor Sociale Geschiedenis

\title{
Crossing the Boundaries? Dynamics of Contention Viewed from the Angle of a Comparative Historian
}

\author{
THOMAS WELSKOPP
}

Comparative social history is still grappling with the problems raised in the debate about history's "cultural turn". And while a new "social turn" seems imminent at the moment, this means a new departure into an actororiented analysis of institutions (including social movements and all forms of contentious politics) beyond the "cultural turn", incorporating a host of compelling insights into the cultural constitution of social reality - and not a return to the old simplistic views of the "modernization era".

With their undoubtedly quite innovative book, Dynamics of Contention, Doug McAdam, Sidney Tarrow, and Charles Tilly move within a slightly different discourse - that within the macrosociological study of collective action and social movements - in order to revolutionize what they call the "classical agenda" in comparative sociology and political studies. Saying this, I do not intend to redraw disciplinary boundaries between history and sociology. My argument is rather that Dynamics of Contention both challenges comparative history and presents an invitation - a suggestion to solve many of the problems that had come up during the debate over the "cultural turn" in history. This is the more so as the authors themselves explicitly relate to history in three respects. First, they want their work to be recognized as historical study. This is to be granted by any means. Second, the authors openly intend to bridge the gap between sociological and historical comparison. Any attempt to cross the boundaries between the disciplines must be highly welcome, because for comparative historians it has been as difficult to establish history as a theoretical field as it has been for historical sociology to win recognition as a historical field. Finally, they consider their approach not only as directed against the "classical" macrosociological agenda, with its functionalist and structuralist history, but also as capable of incorporating some influences they concede to the "cultural turn" in their field. So it must be intriguing for historians to see how the different "concept(s) of culture" (William H. Sewell, Jr) are dealt with in a framework that, on the other hand, ventures to revive macrosociological explanation by means of comparison. Dynamics of Contention might present a model solution for a comparative social history beyond the "cultural turn".

What's in the package for historians? There is - foremost - a mode of 
theorizing that presents itself as flexible, dynamic, and relational; all these are necessary prerequisites for fruitfully applying theory to historical contexts. Moreover, there is a high sensibility towards historical processes, to situatedness in time and space, and to contingency. And yet this is coupled with a whole toolkit of theoretical instruments designed for excavating what quite different times and quite diverse situations might have in common. This is amply demonstrated by the special kind of comparison done throughout the book: the structured (that is, selective) paired comparison of unlikely cases. If they work in drawing together "strange bedfellows", so to say, the theoretical tools ("mechanisms") prove their analytical value and explanatory power across more than the cases under scrutiny. They even may demonstrate that the "unlikely cases" are just variations of a structurally very likely process. This, again, adds to this approach's charm for comparative historians, since it actually makes episodes of change within the system ("contained contention") and those of system-change ("transgressive contention") comparable in the first place.

What can historians learn from today's comparative macrosociology as charted in Dynamics of Contention? My first impression is that macrosociology has moved still closer towards social history, whereas history, in general has taken a rather different course in the meantime - away from sociology and towards other disciplines such as cultural anthropology, cultural studies, and literature. Comparative macrosociology seems to have learned from social history - with the effect of solving some of its own disciplinary theoretical problems while, ironically, importing some of the problems that seemed specific for history when under pressure from the "cultural turn". Dynamics of Contention makes a strong case for inductive theory-building by systematic comparison. The authors eschew both "theories of societies" and typologies of social change, justifying the first by pointing to the dangers of reifying or anthropologizing metatheories of societal entities and fixed causal relations within them, and the second by pointing towards the pitfalls of isolating types of social change from their context in time and space, or historical context, so to say. Instead, they provide a vocabulary of categories labelling specific processes between related sets of phenomena. The term "mechanism" for these categories seems useful and of eminent descriptive value. Yet it remains debatable how far-reaching the causal assumption is in the case of the numerous mechanisms introduced throughout the book; some mechanisms seem more equal than others. This question is amplified by the declared search for "robust" mechanisms which I translate as the quest to look for mechanisms that are decisive in contentious episodes regardless of type, time, and space; the adjective "robust" entails the assumption that the "mechanism" in question can be treated as an independent variable.

The theoretical value of the categories is above all heuristic: they serve to identify connections, systemic relations, and recurrences between 
elements of social processes in their historical context. They then provide an abstract descriptive terminology for a wide range of comparisons. The result of the comparative analysis is the account of episodes in their respective historical context organized by the categories, and the typological arrangement of episodes from "robust" to "puzzling" to "dissimilar". This procedure allows for an innovative way of generalization: instead of talking about "revolutions", "wars", "democratization", or "social movements", the authors lay out various, but presumably invariant, elements of contenious politics, which, in their specific constellation in concrete time and space, decide which form a social process will assume and what results it may produce. The categorical apparatus may be refined during the analysis. This seems to be done by specifying the adequate level of abstraction one should aim at when defining a "mechanism". "Democratization" thus becomes but one form of "contentious politics". The theoretical refining process seems to have a catalogue of universally applicable categorical tools - mechanisms - in view, just like the most basic of Max Weber's "ideal types". Generalization, therefore, does not occur in the shape of ever more sophisticated model construction. Rather, it operates by allowing for an increasing scope of comparison among an increasing scope of historical "episodes".

Social and cultural historians will welcome the Dynamics of Contention project to establish comparative macrosociology as an historical discipline, taking the context and taking time and space much more seriously than other sociological approaches (although not more than "praxeological" approaches). Social and cultural historians should also welcome the authors' determination to jettison all traits of hidden ontology or tacit anthropological constants that "grand theory" tended to proliferate - be it in the disguise of structural functionalism, of modernization theory, or of historical materialism. In history, and in German history in particular, the ontological agenda had been set by "historicism" in the nineteenth century, which portrayed the "substance" of history as the continuous evolution of "ideas" by great personalities. German social history challenged this view during the I970s, and replaced it with a vision of vast socioeconomic processes propelling social and political change actually a "materialist" reversal of "historicism". Therefore, it has been a decisive step to eliminate all forms of historical metaphysics when dealing or operating with theory. "Praxeological" approaches like Anthony Giddens's "structuration theory" have done this by analytically separating "social ontology" - or "social theory" in Giddens's words - from "theories of society", which are all firmly grounded in time and space and, therefore, historically specific and variable.

The strategy applied in Dynamics of Contention is different. The authors suggest avoiding all model construction which builds upon notions of society altogether, and also eschewing any vocabulary which tries to define 
specific classes or types of social change. Instead, they apply their catalogue of universal categories describing causal relations between phenomena - mechanisms - in order both to dissect modes of change into their constituent elements - combinations of "mechanisms" - and to compare these across a wide variety of contexts - "episodes". The descriptive account of historical "episodes", as organized by the parameters the categories of mechanisms provide, becomes the predominant mode of macrosociological representation.

Two questions arise. First, what - if anything at all - still distinguishes this form of comparative analysis from comparative history? Second, should historians follow this theoretical strategy in order to grapple better with some of their problems outlined above?

When measuring the book's account of postcommunist Russia against its claim that analytical narrative in comparative perspective should be the adequate form of macrosociological explanation, it becomes clear that most historical analyses - irrespective of their degree of theoretical sophistication - still mobilize a lot more context evaluation within their explanatory schemes than macrosociology does. The reason for this is systematic: the "mechanisms" are applied as heuristic tools for identifying characteristic elements of social processes in their historical contexts. Yet, at the same time, they both prescribe what qualifies as a respective phenomenon and delimit the beginning, the storyline, and the end of what will be narrated as "episodes". Variable isolation thus comes with the very way the analytical categories are conceived. Many social and cultural historians concerned with establishing the validity of their categories for entangled historical contexts will still feel uneasy about the level of abstraction macrosociological narratives are moving on.

The same is true about the use of comparison. Although broken down into constituent elements, and therefore designated much closer to historical context, category building as well as comparative perspective in the book's approach still follow a universalizing, strategy. The "mechanisms" are decidedly universalizing, in that they are valid for quite diverse classes or types of social change. Yet they actually do not do away with terms and notions of "revolution", "democratization", "war", or "social movements", which are by necessity invoked - even if in a negative way - when trying to find a denominator for the specific cause of events which "mechanisms" have brought about, or the specific constellation in which they combine in a respective historical "episode". And this, in turn, opens up a comparative perspective which not only looks for the maximum number of certain constellations of social change - say "revolutions" - but also for the maximum scope of social processes in which common patterns of "mechanisms" can be identified. To what end? I think that the maximum scope of comparable elements (and, therefore, comparable "episodes") is the new expression of a universalizing socio- 
logical theory beyond the reaches of overarching "universal laws". Yet even for the theoretically conscious among comparative historians, maximizing the number of cases under scrutiny, and maximizing the applicability of theoretical categories in order to maximize the scope of comparison may not be their prime prerogative. Although historical and sociological comparison can communicate with each other, one should acknowledge that there are different perspectives on what comparison should accomplish, that they all may be valid strategies of analysis, and that the macrosociological approach cannot claim to represent the most comprehensive level generalizations may reach in the social sciences.

Certainly, the "historical turn" comparative sociology has taken in Dynamics of Contention has made it interesting again for social and cultural historians, and its new terminology will indeed prove useful for many future historical studies of social change. Yet, I will argue that this approach does not solve history's theoretical problems which actually might become common problems in the near future: the problem of causality, the problem of constructing the social "agent", the problem of bridging the micro/macro divide, the problem of distinguishing (and accounting for) different types of historical dynamics, and the problem of recovering "theories of society" without eventually again being trapped by some form of historical metaphysics.

First, the "mechanisms" approach does depart from a macrosociological view which claims that single invariant causal relations are responsible for processes of social change, reading as, for example: socioeconomic dynamics create social movements which account for specific political outcomes under certain historical circumstances. Instead, its causal logic goes like this: if we detect a specific "mechanism" such as "certification/ decertification" in a context where change has ostensibly occurred, we may find "identity shift" and "object shift" as well. Combined in a certain way they may account, together with other mechanisms in a specific constellation, for social change of a distinct type. If we find a similar or the same constellation of mechanisms across a variety of "episodes" of a kindred character, or a similar set of mechanisms in seemingly different classes of "episodes", we may speak of "robust mechanisms", qualifying as independent variables of analysis for other cases. Causality is implied both with the identification of "mechanisms" in certain contexts as such and with their distinction as "robust". Yet the reasons why and under what circumstances mechanisms come into existence, and how and with what effects they interact, are left open. These questions actually call for a descriptive historical account of cases, if the "mechanisms" themselves do not carry much more implicit causal "weight" than their definition allows for. Therefore, either the "mechanisms" approach cannot make claims to causality other than by referring to regularities and analogies among cases, or it still applies a "mechanistic" assumption of causality, being 
deterministic in the sense that since there is no theoretical model of society to give reasons for variable preference, the causal influence must be built into the mechanisms themselves.

The debate about causality among social and cultural historians today is a slightly different one: It centres around two questions. (I) How can we grasp causal relations in historical societies after the demise of the "basissuperstructure" metaphysics? And (2) what is the theoretical status of "macro" phenomena and their interrelations? First, instead of trying to explain social movements by socioeconomic dynamics, and political outcomes by social movements, social historians should treat economic, social, and political phenomena alike as arenas for social relations and social processes that are not independent from one another but autonomous to a certain degree. Although the ties are what still interest the historian, these interrelations must not be conceived as causal one-way streets. This would allow for shifting and multiple causal relations without reducing one sector of society to an invariant condition for the others. One could even assume that, in modern societies, a dynamic economic sector constantly produces pressures that the political sector has to cope with, but this causal assumption would not lead to a deterministic view of the concrete institutional change brought about by this constellation of factors. Such a perspective could acknowledge that the way people conceive of their environment and construct their worldview deeply influences the way they act: culture in this sense may very well carry a profound causal weight. It could also acknowledge the protracted nature of historical processes which call for a notion of causality that is ready to account for interfering contingencies and "path dependency". Max Weber was right when he distinguished between a sphere of "objectively probable causalities" that invited theoretical construction, and the "adequate causality" detected only in close description of the flow of events. The causal effect of interferences in contingent configurations may even be stronger than the causal relations suggested by theoretical models.

Second, the "mechanisms" terminology seems well equipped to combine a macroperspective with a keen sensitivity towards change on the microlevel of individual "agents". The Russian episode addresses collectivities: "the state" or "ethnic" and "party elites", as well as individuals: regional leaders, or Gorbachev and Yeltsin. Yet, on closer inspection, one can get the impression that the categories themselves are ambivalent or hybrid rather than reconciling or flexible. The "mechanisms" approach does not deal with the construction of the social "agent" explicitly. Moreover, I think that it actually dodges the question of how micro and macro relate to each other by accounting for processes that are more easily understandable on the microlevel of individual "agents", but that are then taken to embody macroeffects or macrodynamics. Take "identity shift" as an example. For me, it is by no means clear how, at 
which level, and when "identity shift" occurs and how it can be wrought into a broad social movement. Are we facing microprocesses that accumulate into macrodynamics? Are we looking at macroeffects of microchange? Do we explain macroprocesses by their microfoundations? It seems to me that it is the macrodimension that still matters most in "mechanisms" analysis.

"Praxeological" approaches that have found their way into social and cultural history centre around a theory that conceives the relation between "structure" and "agency" as a duality. In consequence, it furthers an actororiented and relational analysis of institutions (organizations, relationships, movements) which are viewed as relatively autonomous arenas for social relations and processes. "Macro"-processes, in this perspective, are large scale effects of microrelations, which either are prominent in their importance for the institutional world of society (or are - as organizations - specialized in producing such effects), or bring about cumulative effects for society as a whole. In a certain sense, macroprocesses are microprocesses projected on to a grander scale by means of institutionalization. Any theory of historical institutions, therefore, that proceeds in this "praxeological" vein, will function as a theoretical "zoom" which allows us to switch flexibly and smoothly between "close-ups" on microrelations and "long-shots" of institutional relations. In order to apply actororiented institutional analysis, social history badly needs those very concepts of society that the "mechanisms" approach tries to circumvent.

Third, the "mechanisms" approach centres around process and change, as all its categories are processual in nature. But can it differentiate among different types of change? Can it explain why social change sometimes occurs in the form of sudden events, of condensed "episodes", and sometimes in the form of protracted processes? How can we distinguish between change as a conscious "project" - whatever the unintended consequences might be - and structural change? How can we distinguish between developments within a given system and system transformation? What about processes of reproduction that account for the persistence of institutions or systems? I think that the "mechanisms" approach does provide better answers to these questions than a history which traditionally hovers uneasily between polarized notions of change-as-event versus change-as-evolution.

History has commonly been defined as atheoretical, because it allegedly concentrates on change over time and on a flow of events supposedly contingent in nature. The event-orientation seemed to be characteristic of history, and "event" meant those episodes not accounted for in any theoretical model. Today, social and cultural historians are convinced that traditional history - as the "discipline of time" - is theoretically illequipped to deal with different forms of change and their interaction. There are attempts to establish a "theory of the historical event" in 
historical analysis that draws on Marshall Sahlins or Pierre Bourdieu, for example. Not all episodes narrated by history comprise "events", however. We have to learn to distinguish between "instance" and "event", a distinction more difficult in the German language where the term Ereignis covers both meanings. We have to look for the "dynamics of system reproduction" as well as for structurally determined episodes (which may not crystallize in "events"), or for structural change within systems and system transformation. In consequence, history should adopt theoretical models that allow for the smooth switching between a "slow-motion" perspective on crucial "events" and "episodes" and a "quick-motion" perspective on periods of persistence or protracted structural change. The German term Zeitlupe (literarily "magnifying glass for time") very well denotes the functions such theories may exercise.

Finally, as already outlined in Charles Tilly's Big Structures, Large Processes, Huge Comparisons of I984, comparative macrosociology avoids conceptualizing modern societies as the focus of theoretical synthesis. This move has been motivated both by the quest to overcome the crude determinism displayed by ontological metaphysics or diverse philosophies of history, and by the attempt to avoid implicitly treating "society" and "nation-state" as synonyms. The latter motive targeted a form of comparative history that used nation-states as units of comparison and inevitably produced nothing but national exceptionalisms. There can be no doubt that these reservations are justified. Yet is the "mechanisms" approach a convincing alternative to theorizing modern societies in comparative historical analysis?

The "mechanisms" terminology confines theory to the causal relations it outlines and to potential combinations of such relations that may be found in analysing social and political change. And whereas the categories labelling the "mechanisms" are historically universalizing in nature, the theoretical content of analysis lies within empirical accounts of "episodes" and within the vast array of comparisons the categories make possible. Yet, there is a more or less tacit understanding underlying most notions of "mechanisms" that both the theoretical tools and the units of comparison have modern society as their point of reference. Furthermore, although this approach denounces a typology of social and political dynamics because of its tendency to produce "generic" types of little theoretical and comparative value, it nevertheless makes use of the terminology of "revolution", "war", "democratization", and "social movement" when addressing the "episodes" to which combinations and sequences of mechanisms are applied. Finally, most units of comparison do represent national contexts. These relapses into conventional category construction seem inevitable in order to prevent the analysis of mechanisms from producing free-floating "processes only" pictures of social change, or from becoming absorbed by historical empiricism. Yet, is the aversion to 
addressing the theoretical background of these underlying categories not a serious disadvantage because it allows all kinds of problematic allusions to re-enter the analysis through the back door? Is the "good old" modernization theory (with all its teleological ballast) not lurking around the corner?

For social and cultural history, it seems central to pursue again questions and problems of "theories of society", despite its justified caution about slipping back into deterministic, reifying or all-embracing concepts. Although there is a "history of society", there has so far been little impetus to think "society". There are no ready answers to this quest, of course. But completely shying away from "grand theory" can be no alternative.

I am not proposing to set out on the sterile venture of building a giant theoretical superstructure that at some time will become self-referential and independent from empirical research. Historians are in little danger of swelling the circles of Niklas Luhmann's adepts. I should rather think of a theoretical terminology suited to communicate comparative institutional analyses in one sector of modern society to those in others. It should grasp at the system-specific characteristics of institutions in the three main arenas of social relations and interaction: the complex of firms and markets that constitute capitalist economy, the (private) life-worlds exogenous to capitalist production, and the domain of formal organization in the organizational-political sphere of society. It should link a modern "class" concept (or other advanced and culturally grounded concepts of social inequality) to concepts such as "civil society" and the "modern state" which, taken for themselves, remain one-dimensional. It should provide truly theoretical tertia comparationis for comparison. Modern societies could be envisaged as relatively autonomous yet open arrangements of institutions crystallizing around system-specific "axes of structuration" that integrate (more or less) specific populations across specific time and space distances. As some "axes of structuration" are more regionalized (for instance, the state) than others (for example, capitalism), even the fact that most modern societies are politically and culturally organized in "nationstates" could be explained without collapsing "society" and "nation-state" into one another.

A basic requirement to avoid reification and determinism is the analytical separation between "social theory", addressing the characteristics of all human agency, and "theory of society", which is inherently historical and addresses social systems situated in concrete time and space. Furthermore, institutional analysis has to be strictly actor-oriented: "Society" is agency. Such historical "theories of society" exercise the functions of, on the one hand, organizing empirical research and framing "thick" historical narratives, and, on the other hand, providing a modus of comparison and a basis for generalization. Generalization could produce 
typologies on different levels of abstraction. Typology then would not represent a series of incompatible "generic" phenomena but a spectrum of combinations in which specific structures and processes (different forms of social and political change indeed including "mechanisms") interact or have interacted in historical contexts. Comparative social and cultural history, conceived in this way, could thus contribute its share to the theoretical knowledge of modern societies and at the same time provide "rich" narratives of the past. Dynamics of Contention broadens its scope and enriches its vocabulary, but is itself just the beginning for a comparative history beyond the "cultural turn". 